\title{
Análise histórica da evolução e desenvolvimento dos campos da Ciência e da Tecnologia na antiga União Soviética e Rússia (1917-2010)
}

\author{
Historical analysis of the evolution and the development of the field \\ of Science and Technology in the former Soviet Union and Russia
}

(1917-2010)

ROBERTO LOPES DOS SANTOS JUNIOR

Universidade Federal do Estado do Rio de Janeiro | UNIRIO

\begin{abstract}
RESUMO Este estudo histórico pretende analisar a construção, a consolidação e o desenvolvimento dos campos da Ciência e da Tecnologia na antiga URSS e na Rússia pós-comunista. Inicialmente, serão analisados o período de transição e reorganização desses campos na passagem da Rússia Czarista para a União Soviética; as medidas apresentadas pelo dirigente russo Vladimir Lênin, entre 1917-1922, buscando consolidar o campo científico e industrial russo; as primeiras legislações e políticas propostas durante os anos 1920-1930, passando pela repressão e limitações sofridas por esses campos, tanto nos expurgos stalinistas, a partir de 1936, como durante a Segunda Guerra Mundial. Posteriormente, será feita uma análise da reconstrução e reorganização dessas áreas, no período de 1945 a 1970, quando o país atingiu o status de"superpotência", com um gigantesco e centralizado campo científico e tecnológico. Por último, um exame dos diversos problemas, advindos do colapso da URSS e da adaptação da Rússia a uma realidade capitalista, enfrentados entre 1980 e 2010 aproximadamente, mostrando iniciativas, tanto do partido comunista, como do governo russo no pós-comunismo para atenuar e contornar alguns deles.
\end{abstract}

Palavras-chave infraestrutura em Ciência e Tecnologia - Ciência e Tecnologia na União Soviética - Ciência e Tecnologia na Rússia

\begin{abstract}
Historical study analyzing the construction, consolidation and development of the fields of Science and Technology in former USSR and Post-Communist Russia. Initially, it will be done a study on the period of transition and reorganization of these fields from Tsarist Russia to the Soviet Union; analysis about the measures presented by Russian leader Vladimir Lenin, between 1917-1922, consolidating the scientific and industrial Russian scenario; the first legislations and policy initiatives during the 1920-1930 decades; through the repression and limitations experienced by these fields, both in the Stalinist purges, from 1936 to 1940, and during the Second World War. Subsequently, an analysis will be done about the reconstruction and reorganization of these areas, between 1945 to 1970s, when the country attained the status of "superpower", with a big and centralized Science and Technology field. Finally, a study will be done on the various problems faced by these areas during the 1980s until 2010, arising from the collapse of the USSR and Russia's adaptation to a capitalist reality, showing initiatives of the Communist Party and the Russian government in post-communism to mitigate and circumvent some of them.
\end{abstract}

Key words infrastructure in Science and Technology - Science and Technology in the former Soviet Union - Science and Technology in Russia 


\section{Introdução}

Em relação aos países atualmente classificados como "emergentes", Brasil, Rússia, Índia, China ("BRIC"), ${ }^{1}$ a Rússia é o que, tanto no contexto acadêmico quanto no âmbito jornalístico, apresenta maior número de reportagens e trabalhos paradoxais referentes aos campos da Ciência e da Tecnologia.

Uma corrente, de acordo com algumas reportagens, mostra um país com uma Ciência dilapidada e em crise, mera sombra do outrora gigantesco (mesmo que deficitário e centralizado no complexo militar industrial) campo científico e tecnológico apresentado pela antiga União Soviética.

Por outro lado, artigos recentes apresentam o país com uma infraestrutura científica e tecnológica, embora a duras penas, forte, tentando adaptar seu ainda muito estatizado centro científico a uma realidade capitalista, ao buscar, por exemplo, a criação de políticas de inovação e de estímulos para a produção de patentes, que não existiam antes de 1991. 2 Embora de forma instável, os trabalhos científicos publicados pela Rússia entre 2004-2008 chegaram a 2,6\% da produção internacional, atrás de países como China e Índia, mas à frente do Brasil. ${ }^{3}$

Contudo, de diferentes maneiras, essas abordagens contraditórias, estimularam questões relacionadas à identificação da "real" situação dos campos científico e tecnológico russos. Baseada em alguns desses questionamentos, a presente pesquisa pretende realizar um levantamento histórico, apresentando a evolução dos campos da Ciência e da Tecnologia no país, desde o desenvolvimento e consolidação do poderoso e centralizado complexo científico na antiga URSS até os problemas que, desde 1992, a Rússia vem sofrendo, e as tentativas de adaptações que vem operando, ao tentar integrar tais campos a uma nova realidade capitalista.

Inicialmente, será feita uma análise da construção e consolidação dos campos da Ciência e da Tecnologia na antiga União Soviética, desde os iniciais e conturbados anos do regime comunista, passando por políticas de reorganização feitas nas décadas de 1920 e 1930, e por problemas ocasionados pelos expurgos stalinistas e participação da URSS na Segunda Guerra Mundial. Posteriormente, uma análise da reconstrução desses campos entre 1945 e meados dos anos 1980 - período em que o país atingiu o auge de seu poder científico e tecnológico, com alguns sucessos que justificaram a obtenção do status de "superpotência" - e dos problemas advindos em consequência da manutenção de determinadas políticas e opções para seu desenvolvimento científico. Por último, será estudado o longo processo de crise, desestruturação e reorganização dessas áreas, processo oriundo do colapso e dissolução da URSS e dos instáveis anos da Rússia no pós-comunismo.

\section{Organização e centralização: a Ciência russa nas primeiras décadas da URSS (1917-1945)}

A Ciência russa nos últimos anos do czarismo, apesar de alguns tímidos avanços, passava por problemas como 0 isolamento de seus cientistas de outros campos de pesquisa na Europa, tensões entre os pesquisadores e o errático e confuso patrocínio do governo aos institutos de pesquisa e universidades. Havia campos de excelência no país, como 0 da química, mas, mesmo nestes, ocorriam empecilhos e descontentamentos. ${ }^{4}$

Com a ascensão do governo bolchevique, em novembro de 1917, foram percebidas as primeiras mudanças mais sérias na orientação das políticas científicas do país.

0 premier russo, Vladimir llitch Lênin, acreditando que o desenvolvimento da Ciência em seu país dependia também do acesso aos conhecimentos produzidos nos países capitalistas e temendo que se repetissem os erros da revolução francesa, que destruiu importantes centros de pesquisa por serem do "antigo regime", apoiou medidas que preservassem os institutos científicos da Rússia. ${ }^{5}$ Uma das primeiras medidas tomadas por Lênin foi a de manter a 
autonomia e uma relativa independência do principal centro de pesquisa do país, a Academia de Ciências da Rússia, fundada em 1725, e uma das mais respeitadas da Europa, mesmo com a fria recepção com que o instituto recebeu a revolução e os bolcheviques. ${ }^{6}$ Lenta e gradativamente, 0 governo russo reorganizou a Academia de Ciências nos moldes comunistas, o que só seria realmente consolidado a partir de 1929. Nas décadas seguintes, apesar de políticas repressivas e de alguns expurgos internos, a estrutura do organismo seria consideravelmente aumentada, passando de 1.000 funcionários no final dos anos 1920 para mais de 10.000 no início da década de 1950.7

A partir de 1918, mas principalmente após 1920 com o fim da guerra civil no país, foram tomadas medidas consistentes que reconstruíram o campo científico-tecnológico russo. Nota-se, num primeiro momento, o surgimento de considerável número de universidades e de centros de pesquisa, que permitiram o desenvolvimento de novos estudos e formas de interação entre pesquisadores russos. ${ }^{8}$ Segue-se a criação de diferentes institutos ligados à área militar, econômica ou a campos como medicina e comunicação, cerca de 40 a 70 deles instituídos a partir de 1920, 0 que favoreceu certa descentralização das pesquisas produzidas no país, além de sua melhor fiscalização ou avaliação por órgãos como o Instituto Estatal Técnico Científico (GONTI, fundado em 1920), o Ministério da Educação (mantido pelos bolcheviques) ou o Soviete Supremo da Economia Nacional (VSNKh, fundado em 1918). ${ }^{9}$

Apesar de inevitáveis tensões entre o governo e alguns cientistas, que resultaram em alguns expurgos durante os anos 20, rapidamente os últimos, percebendo a possibilidade de obterem maiores recursos ou de diminuírem seu isolamento de outros campos científicos na Europa, começaram a colaborar de forma mais enfática e efetiva com 0 governo comunista. ${ }^{10}$

A indústria soviética como um todo passou inicialmente por um período em que tentou, na maioria das vezes sem sucesso, preservar sua estrutura, enfraquecida depois de anos de crises e instabilidades e também devido a políticas confusas - e um tanto drásticas - do partido bolchevique, no sistema que ficou conhecido como "Comunismo de guerra" em vigor entre 1918-1921;"11 posteriormente, passou por um processo de reorganização, estatização e nacionalização, por vezes agressivo e marcadamente doutrinário, no programa denominado "Nova Política Econômica" (NEP), em vigor entre 1921-1928, que optou por nela preservar elementos "capitalistas" e por adaptar para o país formas de produção tayloristas-fordistas. ${ }^{12}$

Ainda nos anos 1920, suscitaram-se debates sobre qual caminho econômico a URSS deveria seguir, se o de uma política de patrocínio distribuído entre a indústria e a agricultura, ou o de um investimento maciço na indústria pesada, opção que acabaria sendo a vitoriosa, a despeito de críticas e objeções, logo abafadas, sobre sua real eficácia. ${ }^{13}$

A partir de 1928, com o fim da NEP e o surgimento dos planos quinquenais, surgiram as bases do planejamento centralizado e sistemático da economia russa. Por um lado, consolidaram-se pesados investimentos em áreas ligadas à energia (eletricidade e extração de carvão e petróleo), à indústria pesada (construção mecânica e metalurgia), e à infraestrutura de transportes (estrada de ferro e canais), mas, principalmente, ao campo da defesa, que chegaria a consumir quase $40 \%$ do orçamento soviético. ${ }^{14}$ Por outro, realizaram-se projetos grandiosos ligados a hidrelétricas ou a imensas fábricas, feitos em prazos curtíssimos - e à custa da vida de milhares de prisioneiros políticos - tornando manifesta a "gigantomania" stalinista. ${ }^{15}$

Essas iniciativas tiveram resultados dúbios. Se, por um lado, expandiu o número de indústrias no país e permitiu o surgimento de novos setores relacionados à química, à aeronáutica, à eletrotécnica e à construção de máquinas, por outro, negligenciou setores importantes como 0 da indústria leve e 0 da construção civil, além de imobilizar a URSS com uma política econômica, científica e industrial de metas fechadas e excessivamente controladas, sem estímulos à inovação ou a outras formas de produção, pesquisa e criação. ${ }^{16}$ Tais políticas seriam mantidas, com variações, até 0 final dos anos 1980, semeando nesses campos, após 1991, algumas heranças sombrias.

Estatísticas oficiais soviéticas indicam um considerável aumento - de 543 mil em 1928 para mais de 2 milhões e 500 mil em 1941 - do número de profissionais ligados a intelectualidade ou possuidores de um nível educacional mais elevado. ${ }^{17}$ Alguns dados omitidos nessas pesquisas, como 0 fato de a maioria desses especialistas acabarem 
trabalhando em cargos burocráticos ou longe do campo acadêmico, ofuscam um pouco tais resultados; contudo, foram inegáveis o aumento do número de formandos e a consolidação de uma nova classe intelectual no país (classificada como intelligentsia), com um papel destacado para os engenheiros e os técnicos qualificados.

Praticamente todos os campos de pesquisa sofreram com a repressão cada vez mais agressiva e violenta promovida, a partir de 1936, pelo líder soviético Josef Stalin, período conhecido como o "grande terror". Até aproximadamente 1940, centenas de cientistas foram expurgados de seus cargos e presos; muitos foram executados sob acusações de "traição"; outros sentenciados a longos períodos de exílio em Gulags, ${ }^{18}$ onde muitos pereceram. ${ }^{19}$

Com a Segunda Guerra Mundial, mais especificamente após os alemães terem invadido o país em junho de 1941 , houve uma maciça transferência de indústrias e de empresas - 1.523 entre 1941-1942 - para áreas do Volga, dos Urais, da Sibéria e do Cazaquistão. ${ }^{20}$ Alguns centros de pesquisa e institutos também foram transferidos ou diminuíram drasticamente sua atividade; além disso, em determinados locais, muitos intelectuais e cientistas sofrerem grandes provações e problemas, visíveis em cidades como Leningrado, que sofreu um duradouro cerco das tropas alemãs entre $1941-1944 .{ }^{21}$

Com o término da guerra, projetos de "reparações" foram estabelecidos pelo governo soviético e muito da reconstrução dos campos da Ciência e da Tecnologia do país foi feita por especialistas e pesquisadores alemães que foram para lá realizar estudos e projetos, com material científico e tecnológico confiscado e retirado da Alemanha pela URSS, entre 1945-1949.

Apesar das esperanças de um maior intercâmbio entre os campo científico e tecnológico russos e os do ocidente e a de uma maior descentralização dessas áreas no país, a partir de 1945, iniciava-se a "semimilitarização"22 da Ciência e da Tecnologia soviéticas.

\section{Reconstrução, reorganização e apogeu: a Ciência soviética no pós-guerra (1945 - anos 1970)}

Os campos científico e tecnológico soviéticos, nos primeiros anos do pós-guerra, seguiram por dois caminhos paralelos e por vezes antagônicos.

Primeiramente, os cientistas soviéticos tiveram que se adaptar (muitas vezes sem sucesso) às políticas repressivas apresentadas pelo secretário do comitê central do partido comunista, Andrei Zhadnov (1896-1948), chamadas de zhdanovshchina, que impunham uma forte censura e um rígido controle ideológico aos trabalhos. Muitos dos cientistas e dos pesquisadores foram afastados de suas atividades e, em casos mais extremos, presos ou executados (ainda que a violência nesse período tenha sido menor do que a que vigorou durante os expurgos dos anos 30).

Foi nos campos da Biologia e da Genética, nos quais as autoritárias propostas do pesquisador Trofim Lynsenko prevaleceram, que essa política foi mais visível e intensa, com desastrosos resultados que demoraram décadas para serem reparados. ${ }^{23}$ Outros campos de pesquisa, até meados dos anos 1950, padeceram de problemas parecidos, porém com consequências menos sombrias, graças à intervenção de diversos cientistas (como, por exemplo, o físico Piotr Kapitza) que se opuseram a tais políticas e à intervenção exagerada do partido comunista na Ciência soviética. ${ }^{24}$

A zhdanovshchina evidenciou também um recrudescimento de posturas xenófobas na Ciência soviética, na qual, em diversos campos, houve tentativas, tanto do partido quanto de alguns cientistas, de extirpar o "cosmopolitismo", ou seja, a troca de informações e de material entre cientistas russos e ocidentais. ${ }^{25}$ Apesar de, em tal período, a Academia de Ciências Soviética ter ainda mantido certa independência e de ser a única instituição a receber publicações científicas estrangeiras, ainda assim sofria um forte controle vindo do partido comunista e dos órgãos de informação como o MVD. Mesmo que fosse permitido a certa elite científica desfrutar de algum acesso à informação ocidental, 
parte considerável da Ciência russa não teve o mesmo privilégio, a despeito dos esforços da Academia de Ciências e de alguns pesquisadores e bibliotecários, que tentaram pelo menos atenuar essa situação. ${ }^{26}$

Contrastando com esse fechamento, indícios de um novo e mais robusto sistema ligado à Ciência e à Tecnologia surgiram com a implantação, entre 1949 e 1953, de um Comitê Estatal para a Ciência e Tecnologia chamado de Gostekhinka, e até 1991 denominado GKTN, assim como com a implantação de institutos dedicados à produção e ao controle da informação recebida e gerada no país, como, por exemplo, o Instituto Estatal de Informação Científica e Técnica (VINITI). ${ }^{27}$ Entretanto, medidas realmente concretas que confirmariam essa mudança só seriam vistas após a morte de Stalin, em março de $1953 .{ }^{28}$

Destacam-se também, entre 1948-1953, a construção e a consolidação dos primeiros sistemas de computadores no país (um dos primeiros desenvolvidos na Europa), com destaque para o BESM, MESM, Strela e, o mais duradouro, o ES EVM (em atividade entre a década de 1960 e o fim dos anos 1990). Porém, a partir dos anos 70, esse sistema começaria a sofrer problemas devido a restrições impostas pelo partido comunista, que restringiu muitos dos projetos, além de censurar e perseguir alguns dos principais líderes dos grupos de pesquisa. ${ }^{29}$

Stalin e seu sucessor Nikita Kruschev iniciaram maciços e pesados investimentos em campos como o da física e da cosmonáutica, que, ainda que com altos custos, obtiveram surpreendentes resultados, proporcionando maior prestígio internacional à URSS.

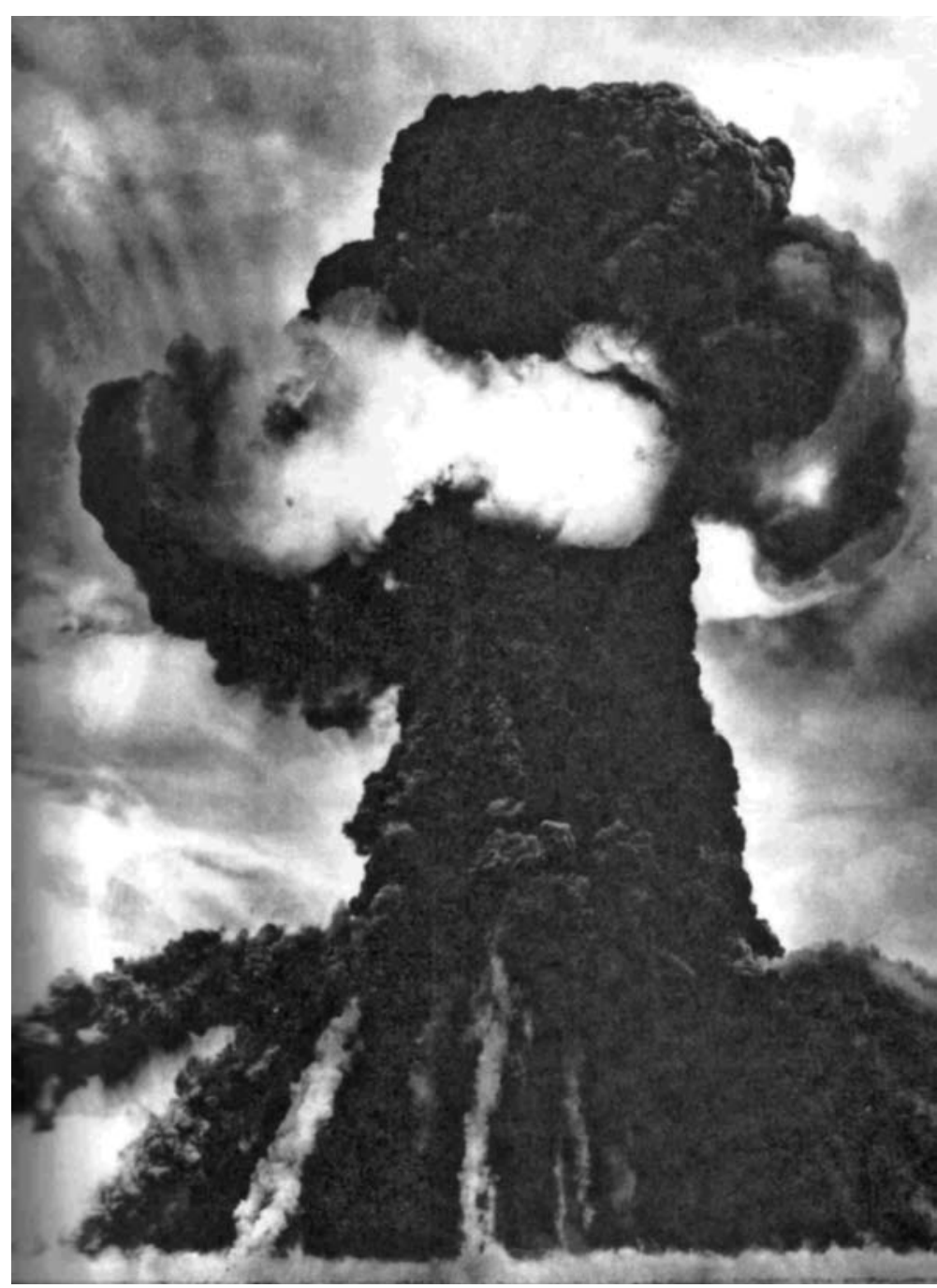

Figura 1 Explosão da primeira bomba atômica soviética, em 29 de agosto de 1949. Fonte: Holloway (1997).
No campo da Física, uma relativa "ilha" de autonomia no "mar" de repressão em que a Ciência soviética mergulhava nessa época, o patrocínio do governo somado, a um grupo de pesquisas eficiente e coeso, sob a firme liderança de Igor Kurchatov (1903-1960), permitiu o primeiro sucesso científico e tecnológico da URSS no pós-guerra, com o teste bem sucedido da primeira bomba atômica soviética, em agosto de 1949, iniciando formalmente o que foi chamado de "corrida armamentista" entre a URSS e os EUA. ${ }^{30}$

A distensão do governo soviético, que fez vista grossa a algumas ideias e teorias banidas durante a era stalinista, e a reabilitação e atuação de pesquisadores e engenheiros cruciais para o desenvolvimento da cosmonáutica, como, por exemplo, Sergei Korolev (1906-1966), conferiram à URSS um papel pioneiro e de vanguarda na construção de projetos ligados a mísseis e ogivas intercontinentais, levando à hegemonia russa na primeira fase da chamada "corrida espacial", com importantes marcos como a primeira viagem ao espaço, feita pelo satélite Sputinik (1957), o primeiro voô com um 
ser vivo (a cadela Laika, em 1957), o primeiro vôo tripulado por um homem (Yuri Gagarin, em abril de 1961) e uma mulher (Valentina Tereshkova, em junho de 1963) e a primeira espaçonave não tripulada a realizar uma alunissagem (Luna 9, em 1966). ${ }^{31}$

As décadas de 1950 e 1960 viram o desenvolvimento e a consolidação do que viria a ser denominado "sistema de informação científica", que se manteve até o final da URSS. Entre 1951 a 1960, foram criadas aproximadamente 1.861 unidades de informação, que visavam suprir organizações e indústrias com material científico ${ }^{32}$ e, a partir de 1954, implantar institutos e comitês de informação científica e técnica nas repúblicas soviéticas, que teriam como objetivo apoiar seus governos, fornecendo informações que dessem suporte às decisões econômicas e administrativas. ${ }^{33}$

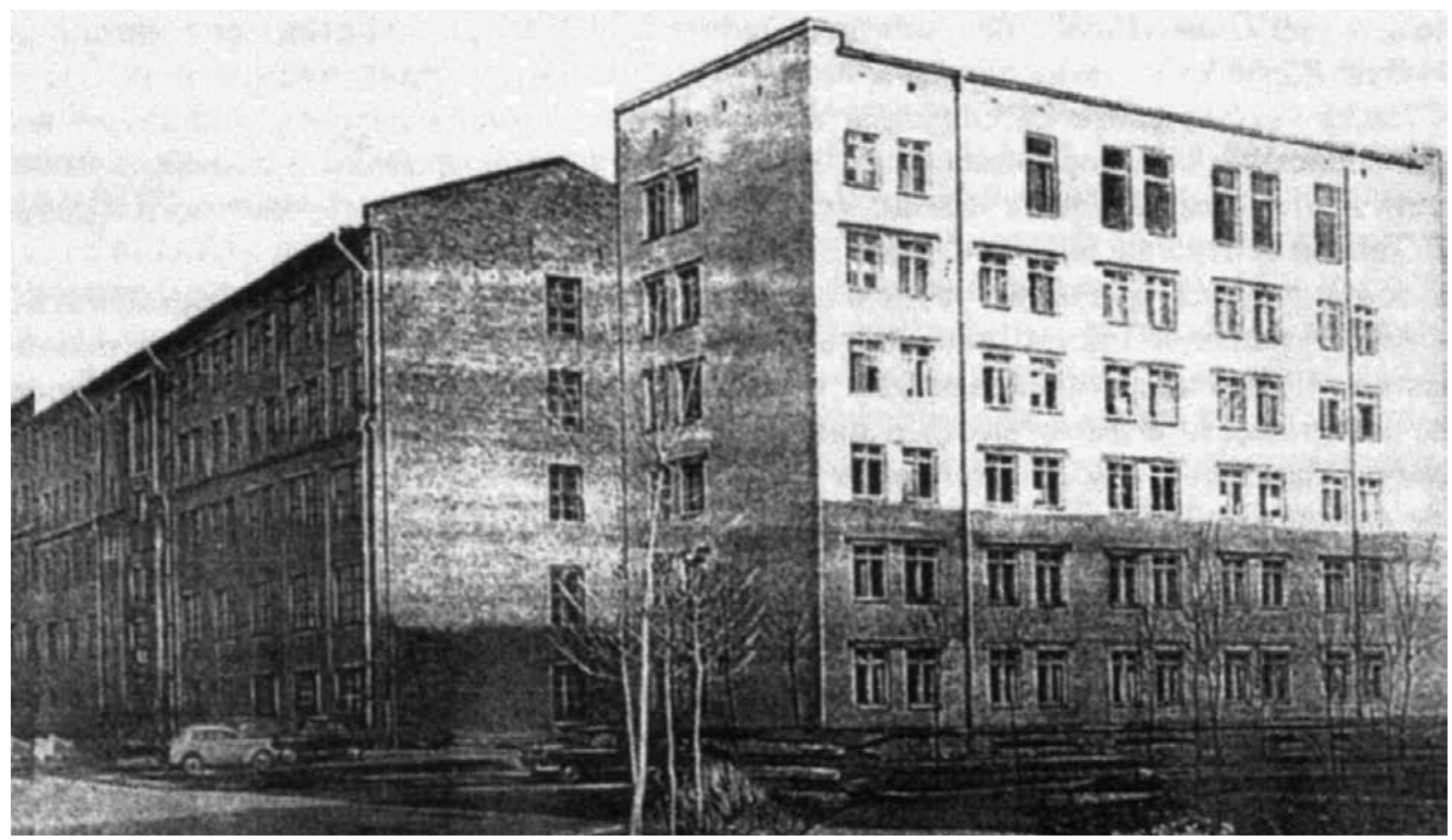

Figura 2 Sede do VINITI em Moscou entre 1952 e 1987 Fonte: Chernyi, 2005, p. 42

Durante as décadas de 1960 e 1970, com a criação de um banco de dados, foram iniciados programas de automatização e informatização, cujo objetivo era interligar diferentes centros de pesquisa e de produção em torno da URSS. Contudo, apesar de algum sucesso, 0 objetivo principal do programa não foi atingido de forma satisfatória. ${ }^{34}$

\section{Consolidando sua estrtura (e status):}

\section{a Ciência soviética nas décadas de 1970 e 1980}

Nos anos 1970, os campo da Ciência e da Tecnologia soviéticos atingiam o ápice de seu poder e status, identificando e estabilizando os parâmetros de sua estrutura e funcionamento, após décadas de políticas centralizadas e muitas vezes confusas. Nessa década, o campo científico do país possuía dois tipos principais de profissionais. 0 primeiro, em maior quantidade (quase 60\%) era formado por especialistas, pesquisadores ou cientistas ligados à Academia de Ciências ou a instituições científicas que com ela mantinham relação. 0 segundo era constituído por engenheiros ou profissionais ligados a atividades científicas fora da Academia de Ciências. ${ }^{35} \mathrm{Em} 1973$, cerca de 1.375 .000 profissionais estavam envolvidos em atividades científicas ou em projetos ligados à alta tecnologia. ${ }^{36}$ 
Alguns levantamentos, segundo dados de 1974, mostram também que, em relação aos EUA, os soviéticos possuíam o dobro de pesquisadores que recebiam algum tipo de patrocínio do Estado (um milhão e trezentos mil contra 680 mil nos Estados Unidos, em 1976), além de superioridade numérica de cientistas em atividade nas áreas de Física, Matemática, Astronomia, Medicinia, Engenharia e em campos relacionados às Ciências Sociais. ${ }^{37}$ Embora devam ser analizados com cautela, tais dados indicam que a União Soviética conseguia atingir certa paridade científica com os EUA.

Houve também um considerável crescimento de institutos científicos na URSS, que passaram de 3.447 em 1950 para 5.327 em 1975, um aumento de mais de cinquenta por cento em 25 anos. ${ }^{38}$ Somente na República Soviética da Rússia, segundo dados de 1974, existiam aproximadamente 475 instituições de ensino superior, com cursos, em mais de 45 línguas, disponíveis para quase 24 milhões de estudantes. ${ }^{39}$

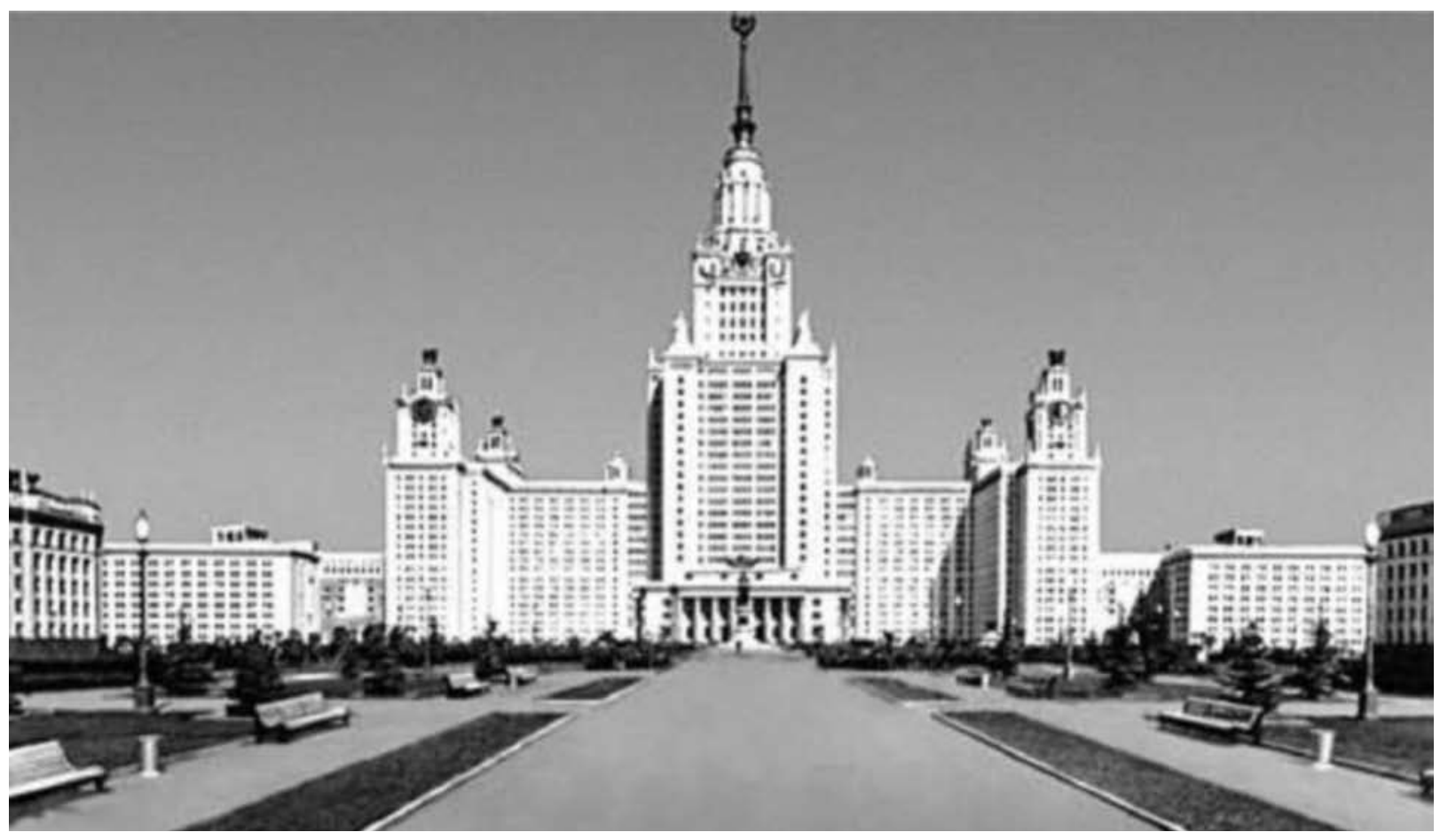

Figura 3 Universidade estatal de Moscou, década de 1970. Fonte: http://www.g-to-g.com/index.php?version=eng\&module=26\#spsu

A Academia de Ciências soviética, que atingiu nessa década o ápice de sua influência e complexidade, era dividida em três grandes centros: um, relacionado à estrutura interna da Academia (funcionários, pesquisadores, projetos de pesquisas, áreas estratégicas); outro, referente ao funcionamento das Academias de Ciências das Repúblicas Soviéticas e, um terceiro, ligado a projetos específicos de diferentes ministérios ou a setores do partido comunista da URSS. ${ }^{40}$

Mas todo esse poderoso aparato, apesar de impor respeito e consideração tanto aos Estados Unidos como à Europa, estimulou também críticas e descontentamentos internos, que começaram a ser ouvidos de forma regular no Ocidente. Primeiro, foram pesquisadores ressentidos com certo "afunilamento" dos campos científico e tecnológico soviéticos, que até possuíam variedade de temas, mas não de locais de estudo ou meios e recursos para sua realização. Outros começaram a questionar o custo humano, econômico e ambiental de tal sucesso, mostrando como algumas partes da URSS estavam pagando um preço alto nesses três aspectos. E, por último, cientistas dissidentes (como Zhores Medvedev e Andrei Sakharov) se opunham à forma autoritária e repressiva - em casos extremos, com o uso de asilos psquiátricos para internar oposicionistas - que o partido comunista empregava para tratar pesquisadores que mostravam alguma visão crítica do regime. ${ }^{41}$ Até o final da era Brejnev, em 1982, contudo, essas críticas tiveram, no campo prático, resultados limitados. 
Além desses questionamentos internos, também uma incômoda e delicada pergunta apareceu nos horizontes científico e tecnológico soviéticos nesse período.

A partir do início dos anos 1970, consolidava-se uma nova realidade, indicando a obsolescência de antigos paradigmas ligados à produção industrial, científica e tecnológica, atingindo diretamente os modelos econômicos tanto dos países capitalistas quanto dos comunistas. Termos como "sociedade do conhecimento", 42 "sociedade pós-industrial", 43 "sociedade da informação", 44 "terceira onda", 45 entre outros, buscavam classificar esse novo e complexo cenário, onde a informação, 0 capital imaterial e as novas tecnologias substituiam ou interagiam com a então dominante forma de produção taylorista-fordista. Caso os países não conseguissem se adaptar, poderiam ocorrer sérios problemas em seus sistemas financeiros e científicos.

Parte considerável dos países capitalistas desenvolvidos (mesmo com variações, resistências e problemas) conseguira ajustar suas economias e políticas a essa nova realidade. E a URSS e o bloco comunista, conseguiriam também se ajustar a esse novo cenário? Principalmente para a União Soviética, esse ajuste seria uma questão de "vida ou morte"46 para a manutenção de seu (cada vez mais fragilizado) status de "superpotência".

Na verdade, essa questão expôs, indiretamente, todas as fraquezas, deficiências, fragilidades e carências do sistema científico-tecnológico soviético, que, em várias áreas, estava distante do das potências capitalistas. Esse questionamento, por outro lado, serviu, também, indiretamente, de norte para as políticass russas no campo da Ciência e da Tecnologia nas décadas seguintes.

\section{A Ciência russa nos últimos anos da URSS}

Os campos da Ciência e da Tecnologia na União Soviética, em meados dos anos 1980, apresentavam duas realidades distintas.

Por um lado, o país, com seu status de superpotência consolidado (porém, como já citado, cada vez mais contestado), possuía centros e áreas de pesquisa que mostravam excelência em nível internacional (como, por exemplo, o VINITI) e uma considerável produção intelectual em várias áreas e disciplinas científicas.

Por outro, neste período, ambos os campos começaram a sofrer, de forma mais nítida e constante, de diferentes e antigos problemas que carregavam desde os primórdios do sistema soviético: uma forte burocracia imposta pelo partido comunista, que não permitia a troca e a divulgação de informações importantes entre diferentes institutos e dificultava 0 acesso e até mesmo a reprodução de documentos científicos; ${ }^{47}$ a forte centralização imposta para a produção e organização da informação, o que prejudicou de forma drástica a maior mobilidade e diversidade de atividades, pesquisas e resultados; 0 estático patrocínio dado pelo governo à Ciência soviética, que se manteve inalterado por quase vinte anos; um atrasado sistema telefônico que impedia uma eficiente interligação entre diferentes centros de pesquisa e institutos científicos russos. ${ }^{48}$

No campo tecnológico, esses problemas se mostrariam bastante incômodos, pois, apesar do citado papel pioneiro da URSS na construção e aprimoramento de um sistema de computadores, ${ }^{49}$ por motivos diversos, este não só ficou em desvantagem com relação ao de outros programas tecnológicos, como, por exemplo, o norte-americano, mas entrou num período de estagnação e ineficiência durante boa parte dessa década. ${ }^{50}$

Em fevereiro de 1986, o então secretário geral do partido comunista soviético, Mikhail Gorbatchev, no $27^{\circ}$ Congresso do Partido Comunista da URSS, estipulou quais seriam as principais dimensões e características das políticas da "Glasnost" e "Perestroika", propostas por ele, no ano anterior. Uma delas, ligada a uma maior democratização e descentralização do sistema soviético, afetaria diretamente os campos científico e tecnológico russos. ${ }^{51}$

Por um lado, a Ciência russa adotou medidas que buscavam uma maior descentralização de recursos e de investimentos, tentando, assim, em várias áreas, diversificar sua estrutura e "fugir" da dependência do complexo militar 
industrial ou da Academia de Ciências Soviética, aos quais estava subordinada. ${ }^{22}$ Por outro, tomou iniciativas para democratizar os centros de pesquisa, universidades e a Academia de Ciências da URSS, buscando estimular uma maior eficiência dos cientistas, bem como tentou promover políticas de inovação e adoção de novos temas de pesquisa. ${ }^{53}$

A partir de leis promulgadas entre 1987-1988, alguns cientistas e engenheiros, de diferentes maneiras, participaram, com alguns sucessos, de pesquisas e trabalhos em diversas "cooperativas" - empresas de pequeno e médio porte que começavam a surgir na URSS -, em especial no campo da computação. Porém, problemas como a abusiva intervenção de institutos de pesquisas estatais, a presença de membros do governo e até mesmo de alguns grupos criminosos nessas cooperativas e sua recepção reservada por parte da população, fizeram com que tivessem um resultado e produtividade irregulares e problemáticos, no início dos anos $90 .{ }^{54}$

No início de 1986, tomava forma outra iniciativa, os Complexos Inter Ramificados Técnicos Científicos (MNKT), espécie de conglomerado que unia diferentes centros de pesquisa ligados às áreas de biotecnologia, química, robótica, automação, entre outras, onde se teria acesso, de forma mais rápida, a novas tecnologias e a meios mais eficientes de administração. Apesar do início promissor, a partir de 1990, problemas ligados ainda à demasiada intervenção do governo soviético e de tensões entre esses complexos com a Academia de Ciências e outros centros de pesquisa estatais emperraram um maior desenvolvimento desses organismos. ${ }^{55}$

A própria Academia de Ciências Soviética, a partir de 1986, sofreria reformas, iniciando um longo período de instabilidade. Inicialmente, uma nova direção e novos pesquisadores e cientistas assumiram postos importantes no organismo, com a missão de reformular e renovar sua estrutura, tanto na Rússia, como nas outras Repúblicas Soviéticas. Entretanto, logo eclodiria um confronto de "facções" entre esses novos cientistas e os antigos acadêmicos que detinham o poder de decisão dentro do organismo e que mostraram forte oposição a mudanças. ${ }^{56}$

A partir de 1989, protestos começaram a eclodir na Academia, além de críticas abertas de ambos os lados começarem a circular em periódicos científicos russos, tornado o clima no instituto cada vez mais instável. A "última batalha" entre essas duas facções ocorreria entre 1990-1991, quando os cientistas mais novos demandaram que fosse criada uma Academia de Ciências Russa, em separado da Academia de Ciências Soviética. ${ }^{57}$ Os pesquisadores mais antigos, além de se oporem a essa proposta, apoiaram, de forma discreta, o golpe dado pela ala conservadora do partido comunista em Mikhail Gorbatchev, em agosto de 1991. Com o fracasso do golpe e a dissolução da URSS no final daquele ano, houve a impressão de que a "antiga" ala da Academia de Ciências perderia seu poder e que sua estrutura se modificaria consideravelmente, fatos esses que, por diferentes fatores, acabaram não acontecendo. ${ }^{58}$

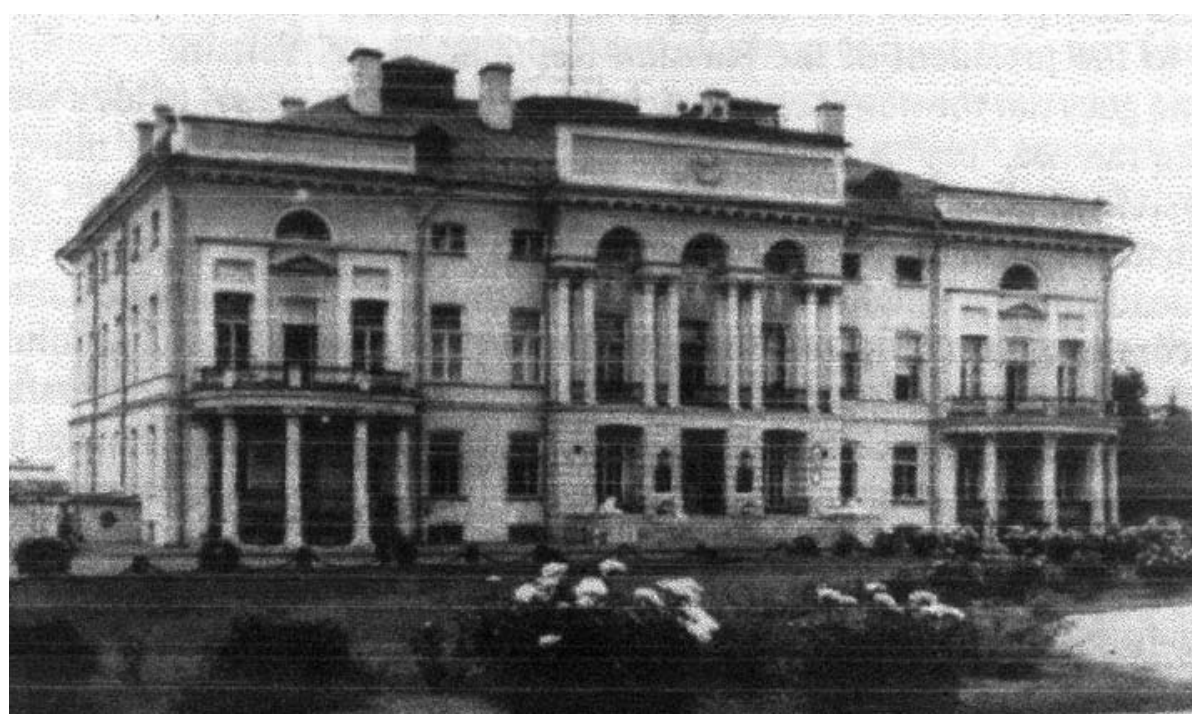

Figura 4 Sede do presidium da antiga Academia de Ciências da URSS, 1991. Fonte: Graham, 1992, p.67. 
Muitos cientistas russos, com a perspectiva de uma realidade mais democrática com o fim do comunismo, criaram esperanças de que a situação da Ciência, após esse período instável, caminharia para uma fase de melhorias e desenvolvimento. Entretanto, tais esperanças, em pouco tempo, se transformariam em decepção.

\section{A caótica situação da Ciência russa nos primeiros anos do pós- comunismo}

0 período entre a desintegração da URSS e 1996, aproximadamente, pode ser considerado como um dos mais críticos para os campos da Ciência e da Tecnologia na Rússia. Diferentes estudos indicam que, com um corte de aproximadamente $20 \%$ em sua estrutura, apenas no ano de 1992, a Ciência russa sofreu perdas consideráveis, no campo da pesquisa e seu desenvolvimento..$^{59}$

A antiga estrutura científica soviética, longe de ser totalmente dilapilada, deu mostra de profundas mudanças, com o fim ou adaptação de projetos e investimentos para uma nova realidade não comunista, mudanças que se mostraram complexas e, em certos setores, traumáticas, pela forma abrupta e até mesmo caótica como ocorreram. ${ }^{60}$

A vertiginosa e abrupta queda de recursos (e prestígio) foi um dos fatos mais marcantes dessa crise. Em casos mais extremos, alguns cientistas, sem pagamento ou qualquer tipo de remuneração, chegaram a se ligar a atividades, grupos ou instituições não oficiais, por vezes ligadas à máfia russa, com pesquisas sobre temas obscuros e de caráter duvidoso. ${ }^{61}$ Outra consequência marcante foi a fuga em massa de cientistas para outras atividades profissionais e para centros de pesquisa nos EUA, Europa Ocidental e Israel, causando lacunas no campo científico do país, situação que só conseguiu ser parcialmente controlada e revertida no final dos anos $1990 .^{62}$

Alguns cientistas buscaram também alternativas e financiamento para suas pesquisas em diferentes empresas privadas que surgiam no país nesse período, iniciativa que beneficiaria uma maior diversificação profissional desses pesquisadores, que começavam a vislumbrar outras oportunidades, para além do então confuso campo científico estatal russo. ${ }^{63}$

Esse período, porém, não foi marcado somente por abruptas perdas ou por uma violenta "crise de identidade". Em 1992, o governo russo tomou medidas para preservar parte da infraestreutura científica do país, a partir de (estranhas e incompletas) emendas e leis, que muitas vezes "implementavam" pesquisas ou políticas que ainda não existiam ou que estavam presas à realidade da antiga União Soviética. Se, por um lado, essa postura permitiu a sobrevivência de importantes centros, também pouco fez para afastar alguns vícios como, por exemplo, uma centralização excessiva de poderes e recursos para alguns cientistas "privilegiados". ${ }^{64}$

Ainda nesse ano foi criada a Fundação Russa de Pesquisa Básica (RFBR), orgão que ajudou a organizar, selecionar e dividir os investimenos do país para os projetos, instituições, grupos de pesquisa ou cientistas que buscavam algum tipo de patrocínio para seus estudos. Em 1994, foi criada a Fundação Russa para as Humanidades (RFH), destinada a alocar recursos para pesquisas em áreas ligadas às Ciências Humanas e Sociais. Apesar de alguns problemas - e de reclamações de alguns pesquisadores -, ambas as fundações se consolidaram como um dos mais importantes centros de recursos financeiros para a Ciência russa, substituindo parcialmente a excessiva, e muitas vezes abusiva, centralização de recursos existente durante a URSS. ${ }^{65}$

No campo internacional, destaca-se a considerável ajuda externa, principalmente a de organismos norteamericanos, de caráter público ou privado (como, por exemplo, os investimentos feitos pelo bilionário George Soros), que, de alguma forma, ajudaram o campo científico russo a não entrar em um total colapso nesses primeiros anos. ${ }^{66}$ Contudo, muitas dessas ajudas foram encerradas, interrompidas ou modificadas, a partir de $1996 .{ }^{67}$ 


\section{Reformas e (tentativas de) recuperação}

0 ano de 1996 seria marcado como o início de um período em que a Rússia buscava alguma estabilidade política, econômica e também alguma recuperação do terreno perdido em seu campo científico e tecnológico. A partir deste ano, novas medidas foram apresentadas pelo então presidente Boris Yeltsin, buscando regulamentar os institutos de pesquisa, que foram mantidos após sua (tumultuada) reeleição. Entre elas, citam-se leis promulgadas em 1997 e 2000, que tentavam incentivar a participação do capital externo em pesquisas científicas ou projetos tecnológicos no país, fosse na esfera pública ou privada. ${ }^{68}$

0 caos voltaria a aparecer na cena científica russa entre 1998-1999, durante a grave crise econômica em que 0 país mergulhou nesse período. Entretanto, em parte devido às já citadas medidas apresentadas em anos anteriores, o campo científico russo, apesar de alguns percalços, como, por exemplo, uma nova diminuição de investimentos, conseguiu, a curto prazo, atravessar essa crise sem maiores consequências.

Nesse período de "reação" da Ciência e da Tecnologia russas, outras iniciativas foram implementadas buscando diversificar as opções científicas do país, ainda muito restritas às universidades ou à Academia de Ciências.

Uma delas foi a criação das "cidades tecnológicas", as primeiras surgidas no país entre 1990-91, que foram apresentadas, a partir de 1997, como uma alternativa para a consolidação de centros de pesquisa de considerável qualidade na Rússia. Alguns sucessos foram obtidos, principalmente em Moscou e São Petersburgo; em boa parte, porém, tais centros mostraram-se pouco produtivos, com problemas estruturais e de desenvolvimento, a serem resolvidos a médio ou longo prazo. ${ }^{69}$

Outra iniciativa que começou também a mostrar seus primeiros resultados, após 1997, foi a construção de zonas econômicas especiais e de centros de inovação, onde diferentemente das cidades tecnológicas, mais ligadas a universidades ou centros governamentais, buscou-se o estímulo da participação de empresas privadas russas e estrangeiras para sua construção e funcionamento (semelhante ao que é realizado por países como China e Índia)..$^{70}$ Até o momento, segundo algumas pesquisas, o resultado mostra-se positivo em algumas delas, sendo, contudo, ainda difícil algum prognóstico a médio prazo. ${ }^{71}$

São características, também com raízes no início dos anos 1990, mas com maior força nesse período, a diminuição do isolamento da Ciência russa com consequentes tentativas de maior integração com os Estados Unidos, Europa Ocidental, Israel, Japão e a manutenção de relações com as antigas Repúblicas Soviéticas e com os países do leste europeu. Como alternativa à busca de recursos apenas junto a agências internacionais, estimulou-se a participação de cientistas, de centros de pesquisa e das universidades russas em projetos e publicações em diferentes áreas, o que, mesmo com certa irregularidade, tem se mostrado produtivo e proveitoso, especialmente com relação à União Europeia. ${ }^{72}$

Estímulos à inovação surgiram também nesse período, com a instituição de prêmios que motivassem a criação de novos produtos e de formas de pesquisa. Entretanto, análises indicam que, apesar de alguns sucessos, no geral, o resultado obtido não tem sido satisfatório. ${ }^{73}$

\section{Novos parâmetros e investimentos: a Ciência russa durante o governo de Vladimir Putin à crise global de 2008}

Após um período de crises e instabilidade, o início dos anos 2000 viu surgir uma nova fase de crescimento econômico e o fim, ou pelo menos o declínio, da caótica situação pela qual a Rússia passava por quase 12 anos, mesmo que tal recuperação, em vários momentos, tenha se dado no bojo de uma política menos liberal, autoritária, do presidente Vladimir Putin. 
Após 2000, os campos da Ciência e da Tecnologia russos entrariam em uma fase de reestruturação com a incorporação de novas, ainda que, em vários momentos, tímidas, iniciativas do governo para (novamente) tentar organizar seus centros científicos e tecnológicos, iniciativas melhor controladas para evitar medidas confusas ou contraditórias como as tomadas entre 1992-1999.74

No geral, não houve grandes mudanças na estrutura científica do país, pelo menos na constituição dos principais centros de pesquisa. Estudos indicam que, no período entre 2000 e 2004, Moscou, São Petersburgo e Novosibirsk continuavam como os principais polos científicos da Rússia, indicando também poucas mudanças na infraestrutura da C \& T no país, em comparação à do período de 1992-94.75

Em relação à produção científica e à visibilidade dos artigos realizados por autores russos, alguns levantamentos afirmam que, no período entre 2001-03, a produtividade no campo da pesquisa, manteve-se alta,, com considerável citação dentro e fora do país. ${ }^{76}$ Entretanto, também aqui, havia centralização, com dois ou três centros respondendo por grande número dos trabalhos citados, contrariamente ao reduzido número na maioria dos outros centros, conforme mostra a figura a seguir (os círculos escuros indicam a proporção de trabalhos que receberam citação no Science Citation Index).

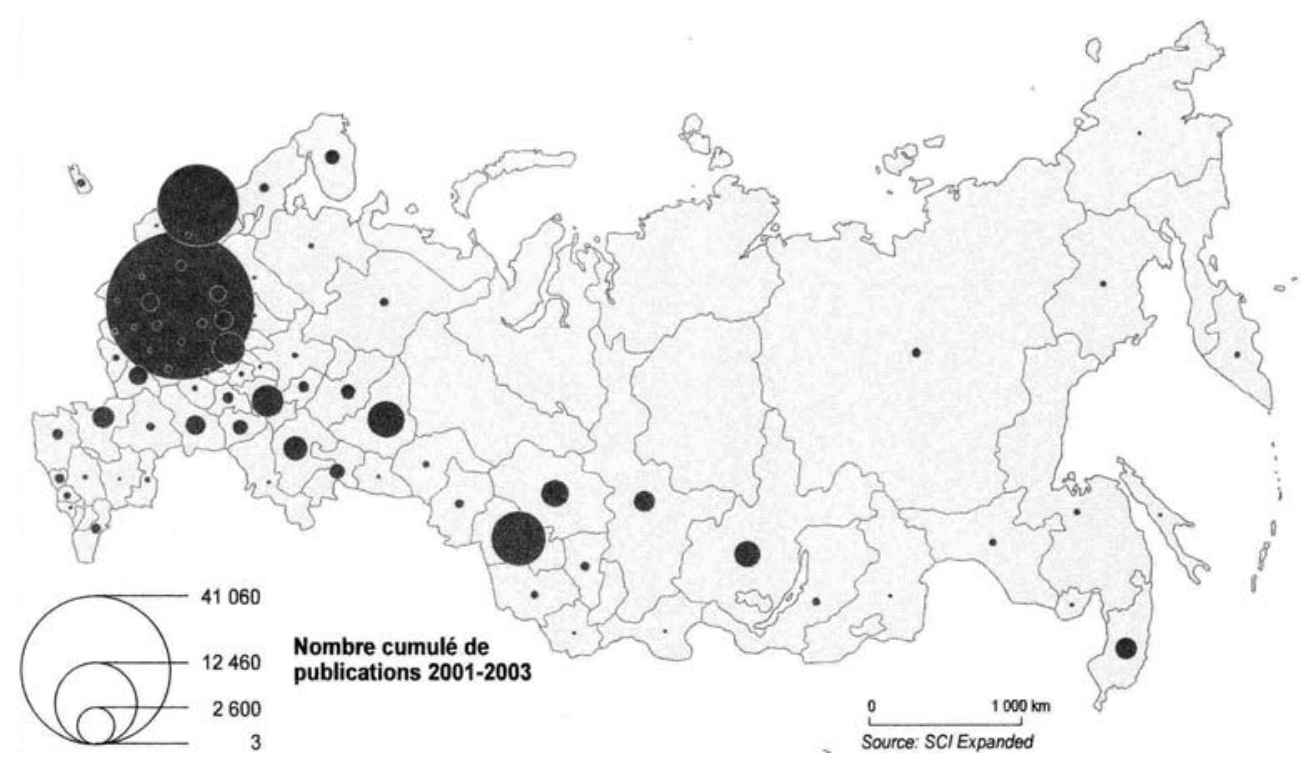

Figura 5 Produção científica das regiões russas no período 2001-2003. Fonte: Millard, Grosseti (2006).

A Academia de Ciências russa sofreria nova reformulação, em dezembro de 2006, com a prescrição por parte do governo de nova estrutura organizacional e de novas prioridades. A curto prazo, porém, tais mudanças se mostraram tímidas, sendo apenas mais uma forma de tornar a instituição mais dinâmica e menos centralizada, um pouco menos "soviética" em sua estrutura, e permitindo ao governo russo retomar parte do controle perdido durante os anos 1990. Alguns problemas do organismo, visíveis desde a época da URSS, como o antigo "choque de gerações" entre cientistas mais velhos, que detinham o poder de decisão, e os mais jovens, que muitas vezes viam prejudicados alguns de seus projetos, mantiveram-se, apesar das tentativas de mudanças. ${ }^{77}$

Outra iniciativa foi a criação ou consolidação de organismos e de novas políticas que estimulassem, de um lado, a criação intelectual e a produção científica no país, com o registro de um maior número de patentes, que até meados da década de 1990, praticamente não existiam na Rússia, e, de outro, as pequenas e médias empresas que começavam a aparecer no país.

Entretanto, em ambos os casos, os sucessos mostraram-se limitados: no primeiro, apesar do número crescente de patentes registradas, a burocracia e a confusa estrutura criada para seu gerenciamento, tornaram restrita sua pro- 
dução. ${ }^{78}$ No segundo, após 2007, percebeu-se um decréscimo do número de empresas de pequeno e médio porte no país, explicado, em parte, pelo interesse das mesmas em serem incorporadas à corporações privadas ou a organismos governamentais, para fugir e, principalmente, sobreviver à instável situação econômica. ${ }^{79}$

Em relação às empresas de grande porte - muitas privatizadas na primeira metade da década anterior - podese observar que, após 2000, algumas apresentaram interessante incremento do nível de inovação e de inter-relação científica e tecnológica com empresas norte-americanas e da União Europeia, mesmo com flutuações e indícios de tentativas de influência interna por parte do governo ${ }^{80}$

A grande maioria das instituições de ensino e de universidades russas continuou em atividade após 1991. Pesquisas realizadas, a partir de 2002, indicam que esses institutos conseguiram de alguma forma obter alguns benefícios advindos de uma realidade mais democrática e menos centralizadora no país. Entretanto, segundo tais pesquisas, os institutos ainda sofrem com a tumultuada transição para o capitalismo na Rússia e com problemas como a baixa taxa de natalidade, a instabilidade da situação econômica e política, a problemática inserção dessas universidades numa nova realidade tecnológica e a diminuição do patrocínio do Estado. ${ }^{81}$

A recuperação ocorrida após 2001 permitiu que a infraestrutura da pesquisa no país suportasse em setembro de 2008, mais uma crise financeira, agora em escala global, com diferentes desdobramentos. A Ciência russa mostraria, contudo, sinais de recuperação e reação a partir de meados de $2009 .{ }^{82}$

Em janeiro de 2010, uma carta assinada por 170 cientistas russos foi enviada para o presidente Dimitri Medvedev, alertando sobre o estado preocupante em que a Ciência e a Tecnologia da Rússia se encontravam, com setores dilapidados, falta de investimentos e fuga de cérebros. ${ }^{83}$ Respondendo indiretamente a esses reclamos, o presidente russo, em meados do ano, anunciou novas medidas, permitindo maior patrocínio público a praticamente todas as iniciativas de reconstrução feitas pelo governo, desde meados dos anos 1990. ${ }^{84}$ Apesar de, aparentemente, essas medidas estimularem a recuperação científica do país e a criação de novos pólos tecnológicos - em especial na construção de um pretenso "vale do silício russo" na região de Skolkovo, próximo de Moscou -, ${ }^{85}$ novamente, as informações sobre como e de que forma seriam feitas mostram-se obscuras ou ainda por definir.

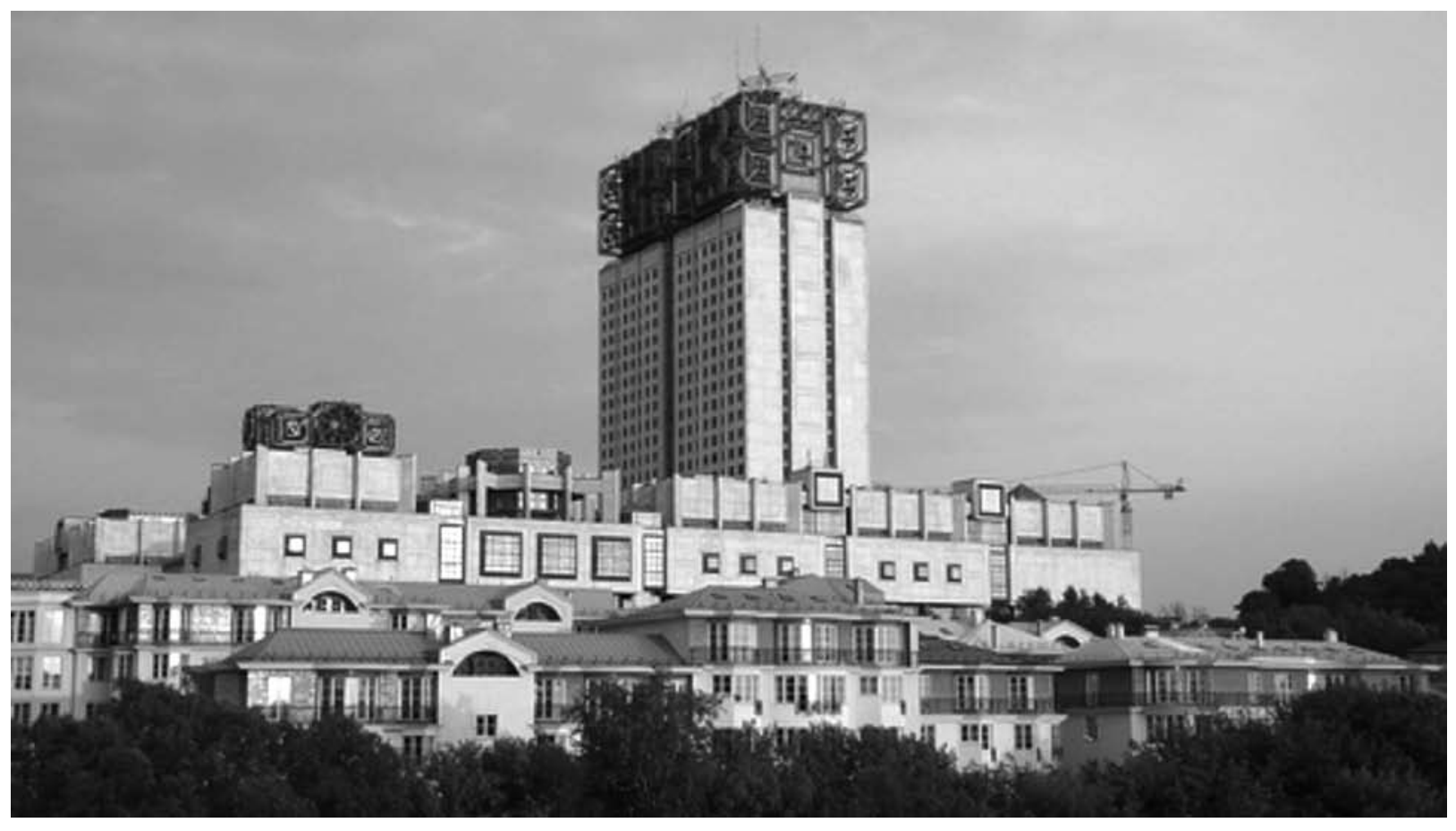

Figura 6 Atual sede da Academia de Ciências da Rússia, 2008. Fonte: Nikolai Kichatov (www.flickr.com/photos/wo_ich/2597603830/) 


\section{Considerações finais}

A presente pesquisa buscou analisar os campos da Ciência e da Tecnologia na Rússia, entre a revolução comunista de 1917 e 2010, tentando identificar as principais características que marcaram essas áreas durante tal período.

Durante quase toda a existência da União Soviética, percebe-se a utilização de políticas altamente centralizadoras, de cunho fechado e, em vários momentos, autoritário e de maciços investimentos econômicos em alguns campos científicos.

Como apresentado ao longo do artigo, por um lado, essas políticas permitiram, num prazo relativamente curto, a transição do país de uma economia agrária e pouco desenvolvida para uma superpotência tecnológica, que chegou a rivalizar e, em algumas áreas, igualar, a dos EUA. 0 campo científico russo atual, de alguma forma, se beneficiou dessa política, possuindo ainda um grande número de formandos e de institutos de pesquisa de respeito em funcionamento.

Por outro lado, esse desenvolvimento teve vários lados negativos: ocorreu em detrimento do de outras áreas econômicas, podando ou restringindo o bem estar da população soviética; teve um alto custo humano em alguns projetos, causando em vários momentos, descontentamento, críticas e, em alguns casos, até mesmo fuga de alguns cientistas; alimentou vícios dos quais a Ciência russa, vários anos após o fim do comunismo, tem ainda dificuldade para se livrar.

Com relação à Ciência russa após 1991, apesar da dificuldade de se chegar a uma conclusão consistente sobre sua condição, pode-se afirmar, que, após 20 anos de uma tumultuada, tensa e instável transição e adaptação para uma nova realidade pós-comunista, ainda que com consideráveis perdas - e em alguns campos com sérias consequências - ela sobreviveu à pior fase da crise (entre 1992 e 1996), com algumas áreas - especialmente a Nanotecnologia - se reestruturando a passos consideravelmente largos, após 2000.

Também se pode notar que o governo russo, apesar da política "neoliberal" muitas vezes inconsequente nos anos 90, teve o bom senso de não dilapidar ou abandonar todo o seu sistema científico (diferentemente do que chegou a ser vinculado na época),o que poderia ter tido consequências sombrias e imprevisíveis.

Entretanto, somente novas pesquisas poderão responder se os campos da Ciência e da Tecnologia russas competem com os dos países desenvolvidos ou com os de nações emergentes como Índia e China.

\section{Notas e referências bibliográficas:}

Roberto Lopes dos Santos Junior é professor substituto no curso de Arquivologia pela Universidade Federal do Estado do Rio de Janeiro (UNIRIO), Doutorando em Ciência da Informação pelo convênio IBICT/ UFRJ. Mestre em Ciência da Informação pelo convênio IBICT/ UFF. E-mail: bobblopes@hotmail.com.

1 Acrônimo para Brasil, Rússia, China e Índia.

2 RADOSEVIC, Slavo. Patterns of preservation, restructuring and survival: science and technology policy in Russia in post-Soviet era. Research Policy, v. 32 , n. 6, p. 1105-1124, 2003; YEGOROV, Igor. Post-Soviet Science: Difficulties in the transformation of the R\&D systems in Russia and Ukraine. Research Policy, v. 38, n. 6, p. 600-609, 2009.

3 BANKS, Michael. Russian Science in a State of decline. Physicsworld.com, 26/01/2010. Disponível em: < physicsworld.com/cws/article/news/41514> . Acesso em: 9 nov. 2011.

4 KOJEVNIKOV, Alexei. The great war, the Russian civil war, and the invention of big science. Science in Context, v. 15, p. 239-275, 2002.

5 RICHARDS, Pamela Spence. Scientific information for Stalin's laboratories, 1945-1953. Information Processing \& Management, v. 32, n. 1, p. 77-88, 1996.

6 PIPES, Richard. Russia under the Bolshevik Regime. Nova York: Vintage Books, 1995; SANTOS JUNIOR, Roberto Lopes dos; PINHEIRO, Lena Vania Ribeiro. A infraestrutura em informação científica e em Ciência da Informação na antiga União Soviética (1917-1991). Encontros Bibli, Florianópolis, v. 15, n. 1, p. 24-51, 2010. Disponível em: < http://www.periodicos.ufsc.br/index.php/eb/article/view/9355/12529 > . Acesso em: 2 nov. 2011.

7 BEYER, R.; KOJEVNIKOV, A.; WANG, J. Purges in comparative perspective: Rules for exclusion and inclusion in the scientific community under political pressure. Osiris, v. 20, p. 23-48, 2005.

8 KOJEVNIKOV, op. cit., 2002, p. 258.

$9 \quad$ Ibid. 
11 CARR, Edward Hallet . La Revolución Bolchevique (1917-1923). Madri: Alianza Editorial, 1974. p. 199-202. v. 2.; FIGES, Orlando. A tragédia de um povo: a revolução russa 1891-1924. Rio de Janeiro: Record, 1999. p. 753-756, 889-892.

12 FIGES, op. cit., 1999, p. 913-914.

13 CARR, op. cit., 1974, p. 329-331; REIS FILHO, Daniel Aarão. Uma revolução perdida. A história do socialismo soviético. 2. ed. São Paulo: Fundação Perseu Abramo, 2007.

14 REIS FILHO, op. cit., 2007, p.125-126.

15 JOSEPHSON, Paul. R. Soviet Scientists and the State: Politics, ideology, and fundamental research from Stalin to Gorbachev. Social Research, v. 59, n. 3 , p. 589-614, 1992; REIS FILHO, op. cit., 2007, p. 126.

16 REIS FILHO, op. cit., 2007, p. 126; GRAHAM, Loren. Science in Russia and the Soviet Union: a short history. Cambridge: Cambridge University Press, 1994.

17 LEWIN, Moshe. 0 século soviético. Rio de Janeiro: Record, 2007. Especificamente no tocante a diplomados universitários, o número passou de 233 mil formados em 1928 para 908 mil em 1941 (REIS FILHO, op. cit., 2007, p. 129).

18 Gulag, Administração Geral dos Campos de Trabalho Correcional e Colônias, era a agência que adminstrava o sistema de campos de trabalhos forçados para criminosos e presos políticos da União Soviética, que vigorou entre 1919 e 1959 aproximadamente. Informações específicas podem ser encontradas em APPLEBAUM, Anne. GULAG: uma história dos campos de prisioneiros soviéticos. Rio de Janeiro: Ediouro, 2004; FIGES, Orlando. Sussurros: a vida privada na Rússia de Stalin. Rio de Janeiro: Record, 2010, e no livro Arquipelago Gulag, escrito por Alexander Soljenítsin, publicado originalmente em 1973.

19 Alguns cientistas puderam, informalmente e às vezes de forma vigiada, realizar pesquisas científicas nesses campos. Outras informações podem ser encontradas em KOJEVNIKOV, Alexei. A grande ciência de Stalin: tempos e aventuras de físicos soviéticos no exemplo da biografia política de Lev Landau. Revista Brasileira de História da Ciência, v. 4, n. 1, p. 6-15, 2011.

20 WERTH, Alexander. A Rússia na guerra. Rio de Janeiro: Civilização Brasileira, 1966. p. 243-254.

21 RICHARDS, op. cit., 1996, p. 78; SANTOS JUNIOR; PINHEIRO, op. cit., 2010, p. 27.

22 JUDT, Tony. Pós-guerra: uma história da Europa desde 1945. Rio de Janeiro: Objetiva, 2008. p. 179.

23 HOBSBAWM, Eric. Era dos extremos: 0 breve século XX, 1914-1991. 2. ed. São Paulo: Companhia das Letras, 1998. p. 514.

24 KOJEVNIKOV, Alexei. Stalin's great science: The times and adventures of Soviet physicists. Londres: World Scientific Publishing Company, 2004. capítulo 8.

25 HOLLOWAY, David. Stalin e a bomba. Rio de Janeiro: Record, 1997. p. 263-265.

26 RICHARDS, op. cit., 1996, p. 85-86.

27 Principal órgão de pesquisa e estudo sobre a informação na União Soviética, e um dos maiores no âmbito internacional. Instituído em junho de 1952, participou de diversos projetos em diferentes campos científicos, muitos deles relacionados à utilização de novas tecnologias no armazenamento e disseminação da informação, sendo alguns em convênio com outros órgãos ou institutos soviéticos. Entre 1975 e 1980, quando, segundo autores, atingiu seu ápice, o VINITI tinha aproximadamente 20 mil funcionários (SANTOS JUNIOR; PINHEIRO, op. cit., 2010, p. 28).

28 Ibid.

29 MALYNOVSKY, Boris N. Pioneers of Soviet computing. 2. ed. 2010. Disponivel em: <www.sigcis.org/files/malinovsky2010.pdf>. Acesso em: 25 out. 2011.

30 Isso, a despeito da utilização indiscriminada de prisioneiros políticos e dissidentes em trabalho "escravo" nesses projetos e de fragilidades que seriam evidenciadas no primeiro desastre nuclear do país, ocorrido na usina de Chelyabinsk-40, em Ekaterinburgo, em 1957, e abafadas na época. Maiores informações sobre o projeto atômico russo estão em Holloway, op. cit., 1997.

31 Maiores detalhes sobre o funcionamento e desenvolvimento do sistema espacial russo / soviético podem ser vistos em GEROVITCH, Slava. New Soviet man' inside machine: Human engineering, spacecraft design, and the construction of communism. OSIRIS, v. 22, p. 135-157, 2007; e em GEROVITCH, Slava. Stalin's rocket designers' leap into space: The technical intelligentsia faces the thaw. OSIRIS, v. 23, p. 189-209, 2008.

32 CHERNYI, Arkaddi. I.; GILYAREVISKYI, Ruggero S.; KOROTKEVICH, L. S. National system of scientific and technical information of the Russian Federation: A draft development program. Scientific and Technical Information Processing, v. 20, n. 2, p. 1-38, 1993.0 número dessas unidades de informação chegaria a aproximadamente 11.000, no final da década de 1970 (PARROTT, Bruce. Information transfer in Soviet Science and Engineering: A study of documentary channels. Santa Monica: Rand Corporation, 1981. p. 11.

33 GILYAREVISKYI, Ruggero. Soviet scientific and technical information system: Its principles, development, accomplishments, and defects. In: CONFERENCE ON HISTORY AND HERITAGE OF SCIENCE INFORMATION SYSTEMS, 1998, Pittsburgh. Proceedings... 1999. p. 195-205. Disponível em: <http://www. chemheritage.org/explore/ASIS_documents/ASIS98_Giliarevskii.pdf > . Acesso em: 25 out. 2011.

34 GEROVITCH, Slava. InterNyet: Why the Soviet Union did not build a nationwide computer network. History and Technology, v. 24, n. 4, p. 335-350, 2008. Disponível em: <http://web.mit.edu/slava/homepage/articles/Gerovitch-InterNyet.pdf>. Acesso em: 3 nov. 2011.

35 NOLTING, Louvan; FESHBACH, Murray. R and D Employment in the USSR. Science, v. 207, p. 493-503, 1980.

$36 \quad$ lbid., p. 495.

37 Ibid., p. 501-502.

38 Ibid., p. 494.

39 Disponível em: <http://en.wikipedia.org/wiki/Russian_Soviet_Federative_Socialist_Republic>. Acesso em: 6 nov. 2011. Esses dados, contudo, também são apresentados com cautela, por não terem sido encontradas outras fontes que confirmem essas informações.

40 LUBRANO, Linda. The hidden structure of Soviet Science. Science, Technology, and Human Values, v. 1, n. 2, p. 147-175, 1993. 
41 MILLER, Robert. The role of the Communist Party in Soviet research and development. Soviet Studies, v. 37, n. 1, p. 31-59, 1985; SERVICE, Robert. The Penguin history of modern Russia: from tsarism to the twenty-first century. 3 ed. Londres: Penguin Books, 2009. p. 415-417; REIS FILHO, op. cit., 2007, p. 222-223.

42 MACHLUP, Fritz; MANSFIELD, Una (Ed.). The study of information: Interdisciplinary messages. New York: John Wiley \& Sons, 1983; DRUCKER, Peter. A sociedade pós-capitalista. 7 ed. São Paulo: Pioneira Thompson Learning, 2001.

43 TOURAINE, Alan. The post-industrial society. Tomorrow's social history: Classes, conflicts and culture in the programmed society. New York: Random House, 1971; BELL, Daniel. The coming of post-industrial society: A venture in social forecasting. New York: Basic Books, 1973.

44 PORAT, Marc. The information economy: Definition and measurement. Washington: United States Department of Commerce, 1977.

45 TOFFLER, Alvin. The third wave. New York: Bantam Books, 1980.

46 HOBSBAWM, op. cit., 1998, p. 409

47 CASTELLS, Manuel. End of millennium. 2. ed. West Sussex: Wiley-Blackwell, 2010; GILYAREVISKYI, op. cit., 1999.

48 SULLIVAN, Water. Soviet scientists often thwarted. The New York Times, Nova York, 1986. Disponivel em: <http://query.nytimes.com/gst/fullpage.html?re $s=9 A 0 D E 5 D 91231$ F934A35753C1A960948260 > . Acesso em: 2 nov. 2011 ; GILYAREVISKYI, op. cit. , 1999, p. 204. Praticamente todos esses problemas seriam percebidos, de forma dramática, no acidente nuclear na usina de Chernobyl, Ucrânia, entre abril e maio de 1986 (ver JUDT, op. cit., 2008, p. 595596), que não só evidenciou a pouca eficiência do campo da C \& T soviético, mas estimulou medidas urgentes que buscaram melhorias nessas áreas.

49 MALYNOVSKY, op. cit., 2010.

50 CASTELLS, op. cit., 2010; MALINOVISKY, op. cit.

51 CASTELLS, op. cit., 2010, p. 49-50.

52 JOSEPHSON, op. cit., 1992, p. 610.

53 bid., p. 610 .

54 GRAHAM, Loren. Big science in the last years of the big Soviet Union. Osiris, v. 7, p. 49-71, p. 63-64, 1992.

55 Ibid., p. 64-65.

56 Ibid., p. 66.

57 Vários organismos e institutos russos, incluindo o próprio partido comunista, eram diretamente relacionados à União Soviética, não existindo deles versões "russas". Esse fato é parcialmente explicado pelo interesse do governo soviético em utilizar a Rússia como uma espécie de "organismo central" da URSS, que interligaria as outras repúblicas ao país. Isso ocasionaria, a partir do final dos anos 1980, um forte ressentimento nacionalista na Rússia, canalizado e utilizado pelo dirigente russo Boris Yeltsin (ver JUDT, op. cit., 2008, p. 646-647; CASTELLS, op. cit., 2010, p. 37-46).

58 GRAHAM, op. cit., 1992, p. 67. Apesar de, em certo aspecto, os pesquisadores mais novos terem obtido uma parcial vitória com a criação de uma Academia de Ciências russa, instituída em 14 de novembro de 1991, e com a extinção de sua versão soviética, em 14 de dezembro do referido ano(FORTESCUE, S. The Russian Academy of Sciences and the Soviet Academy of Sciences: Continuity or disjunction? Minerva, v. 30 n. 4, p. $459-478$, 1992).

59 EGOROV, Igor; CARAYANNIS, Elias. Transforming the post-Soviet research systems through incubating technological entrepreneurship. Journal of Technology Transfer, v. 24, n. 2-3, p. 159-172, 1999. Disponível em: <http://www.uni-klu.ac.at/wiho/downloads/CARAYANNIS POST-SOVIET Rand and_ENTREPRENEURSHIP_-_T2_JOURNAL.pdf. > Acesso em: 2 nov. 2011.

60 GRAHAM, Loren; DEZHINA, Irina. Science in the new Russia: Crisis, aid, reform. Indianápolis: Indiana University Press, 2008.Um panorama sobre as dificuldades da ciência russa nos primeiros anos do pós-comunismo pode ser visualizado em uma reportagem especial da revista Science (v. 264, n. 5163, p. 1259-82, 1994) que analisou os principais problemas sofridos em campos como o da a física, da biologia, da matemática, da astronomia e da cosmonáutica, e ainda em diferentes centros e institutos de pesquisa e ensino.

61 RABKIN, Yakov; MIRSKAYA, E. Z. Science and Technology in the post-soviet disunion. Social Science Information, v. 32, n. 4, p. 553-579, 1993; CASTELLS, op. cit., 2010, p. 189-197.

62 DEZHINA, Irina. American science foundations in Russia as driving forces of international transfer in knowledge and professional skills. In: CONFERENCE - INTERNATIONAL SOCIETY FOR THIRD SECTOR RESEARCH (ISTR), Cidade do Cabo, 2002. Disponível em: < www.istr.org/conferences/capetown/volume/ dezhina.pdf > . Acesso em: 7 nov. 2011.

63 GRAHAM; DEZHINA, op. cit., 2008, cap. 5.

64 Ibid., p. 333-334.

65 Ibid., cap. 4. Em 2009, a RFBR seria o segundo maior patrocinador de projetos científicos em nível mundial, perdendo apenas para o norte americano National Science Foundation

66 Outros organismos que merecem citação são o Centro Internacional de Informação Científica e Tecnológica (ISTC), fundada em 1992, e inicialmente formado por Estados Unidos, Alemanha e Rússia (informações em www.istc.ru) e a Associação Internacional para a Promoção da Cooperação com Cientistas dos Estados Independentes da Antiga União Soviética (INTAS), instituída pela União Europeia, em atividade entre 1993 e 2007.

67 DEZHINA, op. cit., 2002.

68 RADOSEVIC, op. cit., 2003, p. 1115, tabela 8.

69 GRAHAM; DEZHINA, op. cit., 2008, p. 74-76; RADOSEVIC, op. cit., 2003, p. 1116.

70 Atualmente, o país possui em torno de 16 zonas econômicas, as principais localizadas nas cidades de São Petersburgo, Dubna, Zelenograd, Tomsk, Lipetsk e Alabuga.

71 TUOMINEN, Karita; LAMMINEN, Eero. Russian special economic zones. Finlândia: Turku School of Economics, 2008. Disponível em: <http://www.tse. fi/Fl/yksikot/erillislaitokset/pei/Documents/Julkaisut/Tuominen\%20and\%20Lamminen\%201808\%20web.pdf>. Acesso em: 7 nov. 2011.

72 KNYAZEVA, Svetlana; SLASHCHEVA, Natalia. Bibliometric analysis of Russia-EU co-publications. In: FOURTH INTERNATIONAL CONFERENCE ON 
WEBOMETRICS, INFORMETRICS, AND SCIENTOMETRICS \& NINTH COLLNET MEETING. 2008, Berlin. Disponível em: <http://www.collnet.de/Berlin2008/KnyazevaWIS2008rsc.pdf>. Acesso em: 8 nov. 2011); MARKUSOVA, Valentina; AVERSA, Elizabeth. Trends in research performance and international collaboration in Central Asia in the post Soviet period. In: FOURTH INTERNATIONAL CONFERENCE ON WEBOMETRICS, INFORMETRICS, AND SCIENTOMETRICS \& NINTH COLLNET MEETING. 2008, Berlin. Disponível em: < http://www. collnet.de/Berlin-2008/MarkusovaWIS2008trp.pdf>. Acesso em: 8 nov. 2011.

73 NARULA, Rajneesh; JORMANAINEN, Irina. When a good science base is not enough to create competitive industries: Lock-in and inertia in Russian systems of innovation. United Nations University, Maastricht Economic and social Research and Training Centre on Innovation and Technology, 2008.

74 RADOSEVIC, op. cit., 2003, p. 1118-1123. Informações sobre como, no início do governo Putin, essa recuperação e reestruturação ocorreram em alguns centros de pesquisa podem ser encontradas na reportagem feita pelo jornalista Fen Montaigne para a National Geographi, em 2001 (n. 19, ano 2, p. 36-65), que depois de percorrer diferentes polos tecnológicos e de pesquisa discutiu a situação da Rússia pós-URSS.

75 MILARD, Béatrice; GROSSETTI, Michel. L'évolution de la recherche scientifique dans les régions de Russie: déclin ou déconcentration? Mappemonde, v. 86, n. 1, 2006. Disponível em: <http://mappemonde.mgm.fr/num9/articles/art06105.html>. Acesso em 8 nov. 2011.

76 Apesar de dados apresentados pela Thomson Reuters indicarem uma considerável queda de trabalhos científicos produzidos no país, de 29.000 publicações em 1994 para apenas 22.000 em 2006 (CLERY, Daniel. Russian Science: Waking from hibernation. Science, v. 330, p. 1036-1042, 2010.

77 GRAHAM, DEZHINA, op. cit., 2008, p. 37-39; CLERY, op. cit., 2010, p. 1041-1042.

78 COOK, Lisa. D. Where did all the Soviet innovation go? Evidence from Soviet and Russian patents, 1963 to 2007. 2009. Disponível em: <www.hbs.edu/ units/tom/seminars/2007/docs/Where.pdf > . Acesso em: 10 nov. 2011.

79 GRAHAM: DEZHINA, op. cit., 2008, p. 85-87.

80 LIHUTO, Kari; VAHTRA, Peetr. Who governs the Russian economy? A cross-section of Russia's largest corporations. Finlândia: Turku School of Economics, 2009. Disponível em: <http://www.tse.fi/Fl/yksikot/erillislaitokset/pei/Documents/Julkaisut/Liuhto\%20\%20Vahtra\%201209.pdf>. Acesso em: 10 nov. 2011.

81 RICHARDSON JR., John. V. Recent developments in the Russian Far East: The state of education for librarianship. Journal of Education for Library and Information Science, n. 44, p. 137-152, 2003; RICHARDSON JR., John. V. Education for librarianship in the Russian Far East: An update on Vladivostok State University of Economics and Culture. Journal of Education for Library and Information Science, n. 47, p. 160-164, 2006; MARKUSOVA, Valentina A.; MININ, Vladimir A.; LIBKIND, Alexandr N.; JANSZ, C. N. M.; ZITT, Michael; BASSECOULARD-ZITT, Elise. Research in non-metropolitan universities as a new stage of Science development in Russia. Scientometrics, v. 60, n. 3, p. 365-383, 2004.

82 DEZHINA, Irina; KAATERMO, Valtteri. All quiet on the innovation front - The Russian reaction to the economic crisis. Finlândia: Turku School of Economics, 2009. Disponivel em: <http://www.tse.fi/Fl/yksikot/erillislaitokset/pei/Documents/Julkaisut/dezhina_and_kaartemo_1909_web.pdf >. Acesso em: 3 nov. 2011; VAHTRA, Peetr. Expansion or exodus? Russian TNCs amidst the global economic crisis. Finlândia: Turku School of Economics, 2009. Disponível em: $<$ http://www.tse.fi/FI/yksikot/erillislaitokset/pei/Documents/Julkaisut/Nahtra_Russian_TNCs_global_economic_crisis_2009_web.pdf >. Acesso em: 3 nov. 2011.

83 FOX, Maggie. Russia loses Science powerhouse standing. Reuters, 26/01/2010. Disponível em: <http://www.reuters.com/article/ idUSTRE60P14A20100126 > . Acesso em: 30 out. 2011; BANKS, op. cit., 2010.

84 CLERY, op. cit., 2010.

85 A Rússia planeja construir nova cidade científica para competir com o Vale do Silício, UOL Notícias, 10/04/2010. Disponível em: <http://noticias.bol.uol. com.br/internacional/2010/04/10/russia-planeja-construir-nova-cidade-cientifica-para-competir-com-vale-do-silicio.jhtm>. Acesso em: 30 out. 2011.

[Recebido em novembro de 2011, aprovado para publicação em maio de 2012] 